\title{
Decision Making Support for Selecting Structure of Generating Capacities at Development of Local Power Supply Systems
}

\author{
Alexander Nefedov $^{1 *}$, Vladislav Shakirov ${ }^{2}$ \\ ${ }^{1}$ Bratsk state university, Russian Federation, Bratsk \\ ${ }^{2}$ Melentiev Energy Systems Institute SB RAS, Irkutsk
}

\begin{abstract}
This paper considers the problem of multi-criteria option selection for the purpose of developing generating capacities for local power supply systems. The authors suggest a 2-stage method of multi-criteria analysis. At the 1 st stage one conducts a multi-criteria selection of the most prospective power generation technology. At the 2nd stage one conducts a multi-criteria assessment of options for power station capacity ratio on the basis of the selected efficient technology of power generation. At the first stage the authors suggest a modified method of hierarchy analysis allowing for the decrease in the number of requests to a decision-maker (DM). At the second stage the authors use the modified method TOPSIS with the application of value functions for calculating non-linear change of the DM preferences in relation to the assessment of options by the criteria.
\end{abstract}

\section{Introduction}

In compliance with the Energy Strategy of Russia for the period until 2035, an "optimistic scenario" of the energy policy stipulates for a more comprehensive use of the power sector to boost the economic growth and improving the welfare of the Russian population. According to this scenario a higher pace of social and economic development is suggested, especially for the regions of the Russian Far East and Eastern Siberia. This suggestion is connected to the implementation of additional number (more than 100) of investment projects which will involve the growth of demand for energy resources and require making up new energy and industrial complexes [1].

Due to this the priority direction of the energy strategy is forming a sustainable system of energy development of remote territories on the basis of local fuel and energy and renewable resources [1]. The development of eastern region infrastructure requires building local power supply systems (LPSS). This brings about the necessity to select an efficient technology of power production as well as reasonable proportions of power capacities on the basis of selected technology.

At present finding a rationale for developing power supply systems is a multi-stage process, and on each process subsequent stage the previously obtained solutions are specified. The complex nature of this process is defined by the necessity of taking into account multiple significant factors and the uncertainty of future conditions of the power industry developing.
The methodology of validating the development of power industry transfers from centralized state planning to a new system of a multilateral process of validating solutions and making up the mechanisms of their implementation under uncertainty, multiple criteria and multiple diverging interests [2]. These criteria are also fair for validating the options of local power supply systems, which in its turn requires developing an efficient method of selecting the structure of generating capacities (SGC) of LPSS.

In the framework of the described problem this article suggests a 2-stage method of SGC selection which allows excluding inefficient options of power generation during preliminary research and forming the first insight on a SGC with the consideration of multiplicity of purposes and criteria.

\section{2-stage method of multi-criteria selection of LPSS SGC}

While selecting a SGC, depending on the number of available kinds of energy sources and infrastructure regional development a need may arise to compare a larger number of power generation technologies. As a result of such multiple criteria a DM or a group of DM face a complex tasks needing a systematic approach. That is why it is suggested to resolve the problem in 2 stages. Fig. 1 shows the main stages of a 2-stage method of the LPSS SGC multi-criteria selection [3]. 


1st stage - selecting prospective power
generation technology
1.1 Forming reference data on the prospective
development area;
1.2 Forming alternative options of power
generation technologies;
1.3 Forming purposes and criteria of options
comparison;
1.4 Assessing options by the criteria;
1.5 Multi-criteria assessment of options with the
help of the selected method;
2d stage - selecting a generating plant mix
2.1. Forming purposes and criteria with the
consideration of the selected power generation
technology;
2.2. Forming alternative SGC options on the basis
of the selected power generation technology;
2.3 Assessing alternative options by the criteria
with the use of model set;
2.4 Multi-criteria assessment of alternative options
and selecting a preliminary SGC.

Fig.1. 2-Stage method of the selection of LPSS SGC.

At the first stage the authors select the most prospective technologies of power generation from multiple options. This stage includes reference data gathering: defining the value of aggregate electrical load; forming alternative options for power generation technologies which could comprise power plants working at organic fuel (TPP), hydraulic power plants (HPP), wind power plants (WPP), solar power plants (SPP) and other. Further, with the help of a DM one forms a set of criteria and assesses alternative options on the selected criteria. As a result, a set of reference data is formed for subsequent multi-criteria analysis leading to the selection of the most prospective power generation technology.

At the second stage the selection of criteria occurs with the account of the peculiarities of selected power generation technology defined at the first stage. Forming the alternative options of a SGC occurs on the basis of various ratios of the identified capacities of the selected prospective technology and is conducted as follows (Fig. 2). The level of basic power plant capacity with a small manoeuvring ability working with continuous load. The second curve part is covered with power plants the energy resource intake of which cannot be managed. The remaining curve part is covered by manoeuvring stations.

Further, the authors assess the formed SGC options by the criteria with the help of objective and subjective models. The analysis of the SGC economic efficiency is conducted on the basis of assessment of joint power generation by power stations. For example, in case a SGC for power plants is selected in the framework of HPP, TPP, SPP and WPP, power generation at the moment $i$, providing for the fulfillment of HPP technological constraints in terms of capacity, discharge and head-flow characteristics, is defined with the help of the equation systems [3]:

$$
\left\{\begin{array}{l}
E_{T P P i}=N_{T P P i} \cdot \Delta t, \\
E_{S P P i}=Q_{\text {slop.overcast }(i)} \cdot \eta \cdot S \cdot\left(1-k_{t}\left(T_{i}-25\right)\right) \Delta t, \\
E_{W P P}=K_{\text {open }} P\left(v_{i}^{\prime}\right) \Delta t \cdot m_{W P P}, \\
E_{H P P i}=P_{i} \Delta t-\left(E_{H P P_{i}}+E_{W P P i}+E_{S P P i}\right), \\
Q_{H P P i}=\ni_{H P P i} /\left(m_{i} \cdot 9,81 \cdot H_{i} \cdot \eta_{t} \eta_{g}\right), \\
H_{i}=z_{U S i}-z_{D S i}-\Delta H_{i} \\
z_{U S i}=f\left(V_{i}\right) \\
V_{i}=V_{i-1}+\Delta V_{i} \\
\Delta V_{i}=\left(Q_{i}-Q_{W C i}-Q_{D S i}\right) \Delta t \\
\Delta E_{H P P}, \Delta E_{S P P}, \Delta E_{W P P} \rightarrow \min
\end{array}\right.
$$

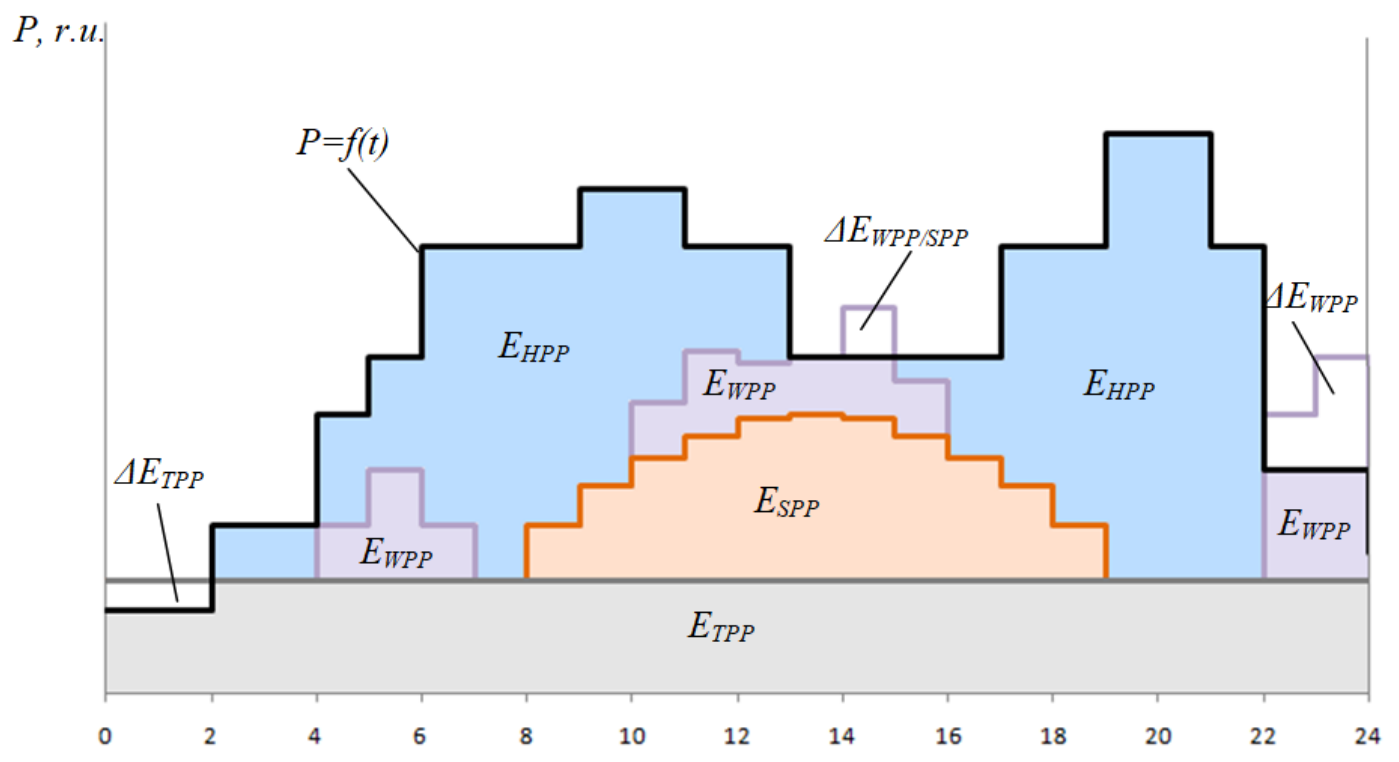

Fig. 2. Daily-load curve and generating power by power generation stations. 
where $E_{\mathrm{TPP} i}, E_{\mathrm{SPP} i}, E_{\mathrm{WPP} i}, E_{\mathrm{HPP} i}-$ generation of various power plant types for each discrete time interval $i$, $\mathrm{kWh} ; i$ - number of discrete time interval $\Delta t=1$ hour during a year; $N_{\mathrm{TPP} i}-\mathrm{TPP}$ capacity, $\mathrm{kW}$; $\mathrm{Q}_{\text {slop.overcast }(i)}-$ aggregate solar radiation received at $i$ hour with the account of cloudiness; $S$ - area of solar panels, $\mathrm{m}^{2} ; \eta$ - efficiency factors of photovoltaic converters, p.u.; $k_{t}$ - grade of change of the efficiency factor of a photovoltaic converter due to temperature change, p.u.; $T_{i}$ - average day-time temperature for the month $i$, grades. $M_{\mathrm{WPP}}-$ number of wind turbines, pcs.; $K_{\mathrm{open}}-$ factor taking into account the terrain relief; $P\left(v_{i}^{\prime}\right)-$ power at wind speed of the $i$-th gradation $v_{i}^{\prime}$ reduced to the rotor height, $\mathrm{kW} ; P_{i}-$ consumer load, $\mathrm{kW} ; Q_{\mathrm{HPP} i}-$ water flow rate, $\mathrm{m}^{3} / \mathrm{h} ; m_{i}-$ number of units in operation; $z_{\mathrm{US}}$ - head race level, $\mathrm{m}$; $z_{\mathrm{DS}}$ - tail race level, $\mathrm{m} ; \Delta H-$ head losses, $\mathrm{m} ; V_{i}-$ reservoir volume, $\mathrm{m}^{3} ; Q_{i}$ - natural inflow to the HPP reservoir, $\mathrm{m}^{3} / \mathrm{h} ; Q_{\mathrm{WC}}-$ consumptive water use above the hydrosystem gate, $\mathrm{m}^{3} / \mathrm{h} ; Q_{D S}$ - flow rate to the downstream side of the dam, $\mathrm{m}^{3} / \mathrm{h}, ; \Delta E_{T P P}, \Delta E_{S P P}, \Delta E_{W P P}$ - non-demanded power of TPP, SPP, WPP, $\mathrm{kW} \cdot \mathrm{h}$.

The approaches towards the alternative options by other possible criteria is presented in [3]. As a result, the authors form a set of assessed alternative options by the criteria. Further, the authors conduct a multi-criteria analysis with the help of the selected method. It resulted in the selection of the most efficient ratios of the established power station capacities. Consider the methods used in the research for multi-criteria analysis of alternative options (steps 1.5, 2.4, Fig.1)

\section{Methods of multi-criteria assessment for analyzing options at selecting LPGS SGC}

A traditional approach towards the consideration of multiple criteria while resolving the problems of LPSS development consists in reducing the problem to a single criterion one by means of identifying one, main criterion and transferring other criteria to a range of limits. Such approach is grounded if there is a mechanism of assigning such limitations in the form of corresponding standards. In case there are no limitations on the criteria and for some reason or another they cannot be explicitly assigned, the problem is considered as a multi-criteria one [4].

Consider the methods selected and upgraded by the authors for applying the problem of a multi-criteria selection of LPSS SGC.

\subsection{Modified method of analyzing hierarchies used to select power generation technologies}

At the first stage (Figure 1) the number of alternative options is approximately 10 , so, it is suggested to use the method of the analytic hierarchy process (AHP) as a tool for multi-criteria analysis [5, 6]. This method is oriented towards the comparison of a smaller number of alternative options, is characterized by a simplicity of perception for a DM and is widely applied at planning the development of power system in foreign countries [7, 8]. The key method concept consists in the fact that a DM conducts pair-wise comparison of options by the criteria and the criteria against each other on the basis of the comparative importance scale (Table 1). The stages of an original method one can find in [5].

Table 1 - Fundamental scale for assessing the effect of judgments [5].

\begin{tabular}{|c|c|}
\hline Importance & Assessment \\
\hline Equal importance & 1 \\
\hline Moderate advantage & 3 \\
\hline Significant advantage & 5 \\
\hline Big advantage & 7 \\
\hline Absolute advantage & 9 \\
\hline
\end{tabular}

One of drawbacks of the method is a significant growth in the number of requests to a DM given the increase in the number of options and criteria. The suggested method modification consisting in building a DM preference model basing upon several requests. The model allows filling option pair-wise comparison matrices without subsequent DM involvement.

Building the preference model consists in the following. While familiarizing the grading scale by the criterion, a DM is provided with the information that the comparative importance assessment $c_{i j}-$ is the advantage the alternative option with the assessment $x_{i}$ has over the assessment $x_{j}$ by the criterion. Further, the authors pose questions the answers to which are defined by the DM preferences in relation to the assessment "moderate advantage -3 " at the alternative option comparison. As a result, one is able to build a preference model of the following type (fig. 3).

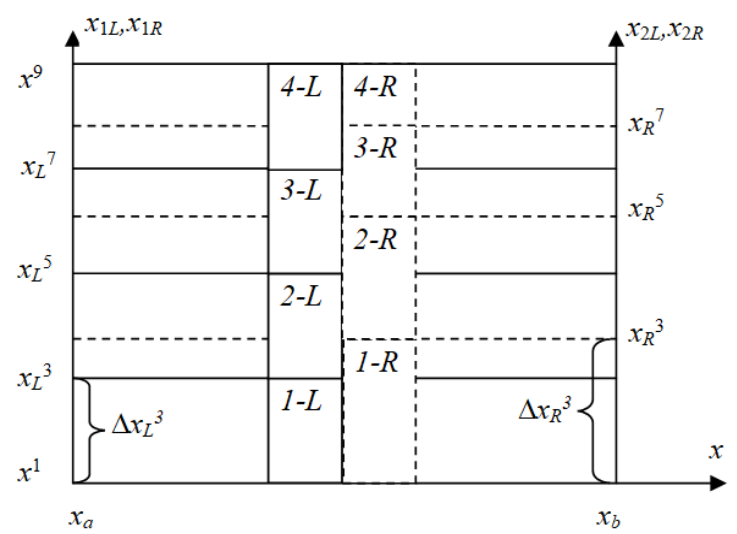

Fig. 3. A possible model of the DM interval preferences

The curve (Fig. 3) $\Delta x_{L}{ }^{3}, x^{3}{ }_{R}-$ explicitly expressed DM preferences in relation to the assessment "moderate advantage - 3 " at the comparison of alternative options. 1- $L, 2-L, 3-L, 4-L$ correspond to the assessment areas $1-3,3-5,5-7,7-9$ at the DM answer$\Delta x_{L}{ }^{3}$ while $1-R, 2-R, 3-R, 4-R$ corresponds to the assessment areas at the DM answer $-\Delta x_{R}{ }^{3}$.

$\mathrm{DM}$ preferences in relation to the assessment values $5,7,9$ are formed on the basis of the equation system [9]: 


$$
\left\{\begin{array}{l}
x^{1}=x_{a} \\
x^{3}=x^{1}+\Delta x^{3} \\
x^{5}=x^{3}+\Delta x^{3} t \\
x^{7}=x^{5}+\Delta x^{3} t^{2} \\
x^{9}=x^{7}+\Delta x^{3} t^{3}=x_{b}
\end{array}\right.
$$

where $x_{a}-$ minimum assessment of the options considered; $x_{b}-$ maximum assessment of the options considered.

On the basis of the preference model (Fig.3) it seems possible to conduct pair-wise comparison of alternative options and get a set of global priorities (Table 2).

Table 2 Set of global alternative priorities $x_{i}$

\begin{tabular}{|c|c|}
\hline $\begin{array}{c}\text { Preference } \\
\text { option }\end{array}$ & Global importance factors $V_{i}$ \\
\hline 1 & $V_{i 1}=v_{1 i L} w_{1}+v_{2 i L} w_{2}+\ldots+v_{n i L} w_{n}$ \\
\hline 2 & $V_{i 2}=v_{1 i L} w_{1}+v_{2 i L} w_{2}+\ldots+v_{n i} w_{n}$ \\
\hline 3 & $V_{i 3}=v_{1 i L} w_{1}+v_{2 i L} w_{2}+\ldots+v_{n i R} w_{n}$ \\
\hline$\ldots$ & $\ldots$ \\
\hline $\mathrm{z}$ & $V_{i z}=v_{1 i R} w_{1}+v_{2 i R} w_{2}+\ldots+v_{n i R} w_{n}$ \\
\hline
\end{tabular}

Table 2 shows $v_{i L}, v_{i C}, v_{i R}$ as local priorities of alternative options corresponding to the limits and the core of fuzzy assessment of the option $x_{i}$ by the criterion. $w_{1} \ldots w_{n}-$ local priorities of criteria.

Each option of the DM preferences $z$ allows obtaining the corresponding ranking for alternative options. The best option is considered to be the case which has a higher rank at a larger number of the DM option preferences:

$$
P_{i}=\frac{z_{i}}{z}
$$

where $z_{i}$ - number of preference options at which the alternative $i$ had a higher rank.

When filling pair-wise comparison matrices the authors obtain perfect match of answers which allows gaining the correct results.

Using the proposed procedure allows for the decrease in the number of requests to a DM at the comparison of power generation technology [9].

\subsection{Application of the TOPSIS method in case of uncertainty of preferences of the DM for selecting the ratio of power plant capacities}

At the second stage (Fig.1), due to a larger number of alternative and fuzzy information on their assessment, it is suggested applying the fuzzy method TOPSIS. The main method concept consists in the measuring the distance of alternative options to an ideal positive and ideal negative solution (IPS and INS). The best option is the one that has the least distance to the first solution and, correspondingly, the longest distance to the second solution. The structure of an original method one can find in [10].

As a DM needs to express the preferences in relation to a SGC for a long-term outlook of several decades, there are difficulties occurring in relation to exact assessment. To take into account fuzzy DM preferences, the authors suggest introducing fuzzy single-criterion value functions (FSCVF) in the method. Fig. 4 presents the FSCVF example at increasing preferences. The building of such FSCVF can be implemented with the use of triangular fuzzy numbers in the DM answers by the method described in [11].

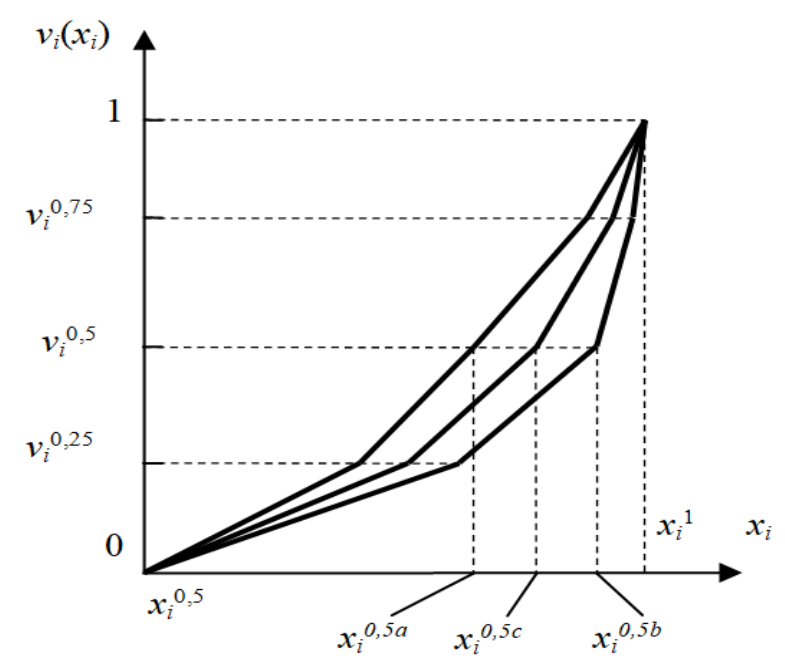

Fig. 4. Fuzzy single-criterion value function at increasing DM preferences

Fig. 4 uses the following designations of assessment varieties by the criteria $x$ and values of assessment by the criteria $v$. A higher index $a$ corresponds to a left, $b$ - to a right limit of fuzzy assessment, $c$ - corresponds to the fuzzy assessment core. Building FSCVF is implemented with 5 check points [11]. The interval from $\left[x_{i}^{0}, x_{i}{ }^{1}\right]$ defines the mean value point $x_{i}^{0,5 c}$ and possible limit conditions $x_{i}^{0,5 a}$, $x_{i}^{0,5 b}$ [11]. In a similar way the authors establish mean value points at the interval $\left[x_{i}^{0}, x_{i}^{0,5 c}\right]$ и $\left[x_{i}^{0,5 c}, x_{i}^{1}\right]$ with the value $\widetilde{v}_{i}^{0,25}$ and $\widetilde{v}_{i}^{0,75}$ correspondingly. Defining a fuzzy value by FSCVF is implemented with the help of a method described in [11].

The use of FSCVF in the TOPSIS method replaces the steps of normalizing according to the provisions and fuzzy numbers are used when accessing IPS and INS.

\section{Application of 2-stage method for preliminary selection of LPSS SGC}

Consider the application of a 2 -stage method by the example of one of the prospective district of the Kamchatka Region.

Stage 1 Step 1.1. The authors form a situation plan of the prospective district development on the basis of $[12,13]$ which has a form (Fig. 5).

On the basis of the analysis conducted for similar objects [14] the authors define preliminary options of consumer capacities and form daily seasonal curves of LPSS load. The maximum load capacity amounted to $77 \mathrm{MW}$. 


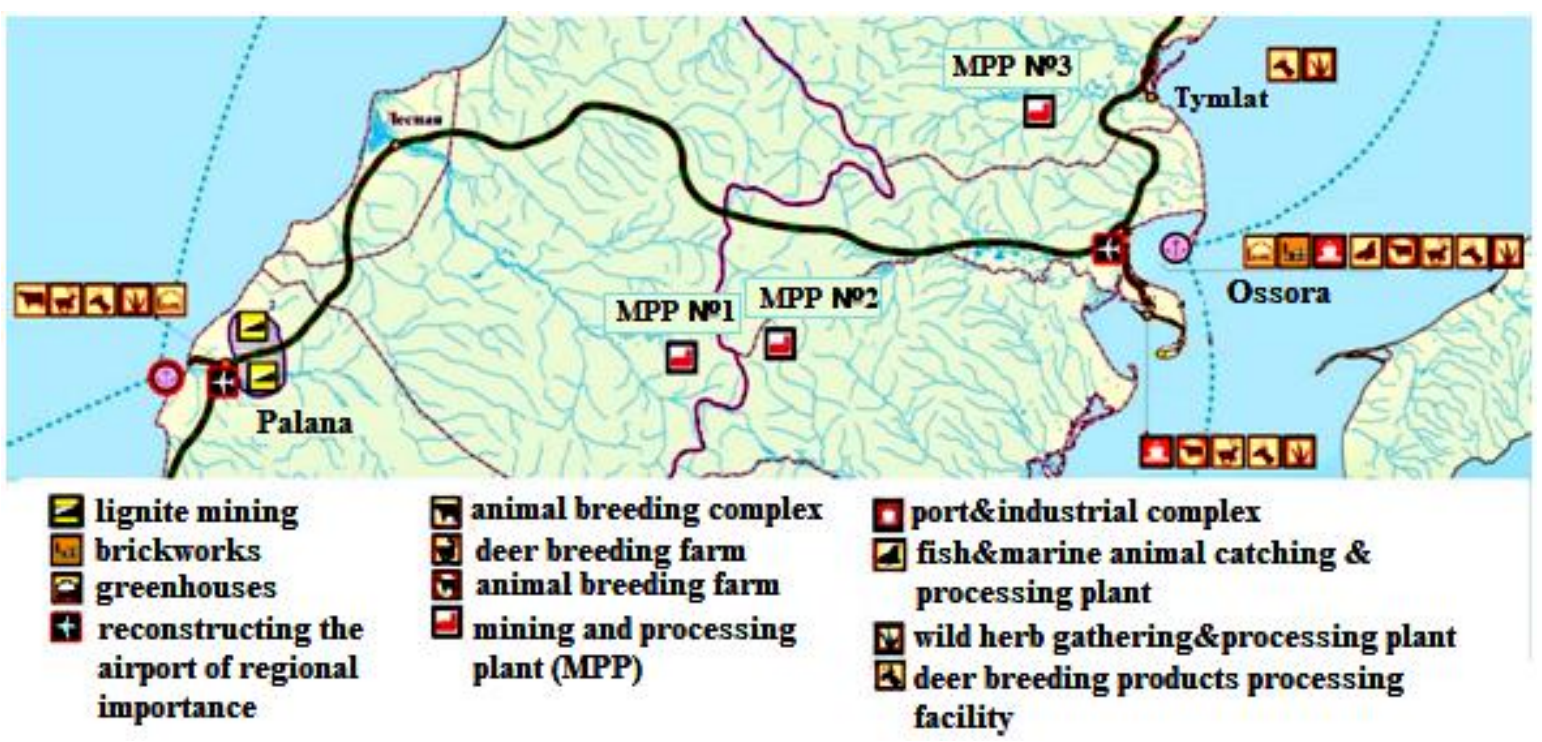

Fig. 5. District situation plan with the location of prospective power consumers.

Step 1.2. The assessment of efficiency of various power generation technologies conducted in [3] demonstrated the following results (Table 3 ).

Table 3 Assessment of energy resources potential.

\begin{tabular}{|c|c|c|c|}
\hline $\begin{array}{c}\text { Coal, } \\
\text { years }\end{array}$ & $\begin{array}{c}\text { Power output by } \\
\mathrm{SPP}, \\
\mathrm{kW} \cdot \mathrm{h} / \mathrm{m}^{2}\end{array}$ & $\begin{array}{c}\text { Maximum } \\
\text { guaranteed } \\
\text { capacity of HPP, } \\
\text { MW }\end{array}$ & $\begin{array}{c}\text { Power output 1 } \\
\mathrm{kW} \text { WPP, } \mathrm{kW} \cdot \mathrm{h}\end{array}$ \\
\hline 70 & 1415,17 & $20,268 \mathrm{MW}$ & 1250 \\
\hline
\end{tabular}

As this region has a well-formed system of diesel fuel supply, the alternative options for the 1st stage are: TPP, HPP, WPP, SPP, DPP.

At the stage 1.3-1.4 a DM helps to form a set of criteria. The 1st stage purpose is selecting the most efficient power generation technology. The authors suggest taking the following as the criteria: $K_{1}-$ net discounted income at using the technology; $K_{2}-$ assessing a comprehensive environment impact of the technology; $K_{3}$ - assessment of public opinion on the plant type $\left(K_{31}-\right.$ population attitude to the manufacturing technology, $K_{32}-$ provision of the population employment); $K_{4}-$ assessing technical efficiency $\left(K_{41}-\right.$ influence of the technology on power quality, $K_{42}$ - energy source manoeuvring ability). These criteria are used to assess alternative options with the help of subjective and objective models. The results are presented in Table 4.

Table 4 Assessment of options on criteria.

\begin{tabular}{|c|c|c|c|c|c|c|}
\hline \multirow{2}{*}{ Options } & \multirow{2}{*}{$\boldsymbol{K}_{\mathbf{1}}$, rubles } & \multirow{2}{*}{$\boldsymbol{K}_{\mathbf{2}}$} & \multicolumn{2}{|c|}{$\boldsymbol{K}_{\mathbf{3}}$} & \multicolumn{2}{|c|}{$\boldsymbol{K}_{\mathbf{4}}$} \\
\cline { 4 - 7 } & & $\boldsymbol{K}_{\mathbf{3 1}}$ & $\begin{array}{c}\boldsymbol{K}_{\mathbf{3 2}} \\
\text { man-year/ } \\
\mathbf{G W} \cdot \mathbf{h}\end{array}$ & $\boldsymbol{K}_{\mathbf{4 1}}$ & $\boldsymbol{K}_{\mathbf{4 2}}$ \\
\hline TPP & $\begin{array}{c}{[70794 ;} \\
92136]\end{array}$ & 1 & 2 & 0,11 & 5 & 4 \\
\hline WPP & {$[47447 ;$} & 3,45 & 4 & 0,17 & 1 & 2 \\
\hline
\end{tabular}

\begin{tabular}{|c|c|c|c|c|c|c|}
\hline & $62387]$ & & & & & \\
\hline HPP & $\begin{array}{c}{[678669 ;} \\
744817]\end{array}$ & 3,95 & 4 & 0,27 & 5 & 5 \\
\hline SPP & $\begin{array}{c}{[134009 ;} \\
144416]\end{array}$ & 2,95 & 5 & 0,87 & 3 & 2 \\
\hline DPP & $\begin{array}{c}{[-761088 ;-} \\
747859]\end{array}$ & 2,47 & 3 & 0,11 & 5 & 5 \\
\hline
\end{tabular}

At building the preference model it is suggested that a DM answered the question in relation to the "moderate advantage" by the criteria in the following way (Table 5).

Table 5 DM preferences in relation to criteria.

\begin{tabular}{|c|c|c|c|c|c|c|}
\hline Criterion & $K_{1}$ & $K_{2}$ & $K_{31}$ & $K_{32}$ & $K_{41}$ & $K_{42}$ \\
\hline$\Delta x_{L}{ }^{3}$ & 150000 & 0,6 & 0,65 & 0,15 & 0,8 & 0,65 \\
\hline$\Delta x_{R}{ }^{3}$ & 200000 & 0,8 & 0,85 & 0,25 & 1,2 & 0,85 \\
\hline
\end{tabular}

Further the authors define importance factors at fuzzy preferences of a DM (Table 6).

Table 6 Local importance factors for alternative options.

\begin{tabular}{|c|c|c|c|c|c|c|}
\hline & \multicolumn{3}{|c|}{$\boldsymbol{K}_{\mathbf{1}}$} & \multicolumn{3}{c|}{$\boldsymbol{K}_{\mathbf{2}}$} \\
\cline { 2 - 7 } & $v_{L}$ & $v_{C}$ & $v_{R}$ & $v_{L}$ & $v_{C}$ & $v_{R}$ \\
\hline $\boldsymbol{A}_{\mathbf{1}}$ & 0,226 & 0,225 & 0,222 & 0,033 & 0,034 & 0,035 \\
\hline $\boldsymbol{A}_{\mathbf{2}}$ & 0,224 & 0,220 & 0,218 & 0,262 & 0,264 & 0,265 \\
\hline $\boldsymbol{A}_{\mathbf{3}}$ & 0,287 & 0,291 & 0,297 & 0,299 & 0,308 & 0,317 \\
\hline $\boldsymbol{A}_{\mathbf{4}}$ & 0,232 & 0,231 & 0,231 & 0,223 & 0,219 & 0,215 \\
\hline $\boldsymbol{A}_{\mathbf{5}}$ & 0,032 & 0,032 & 0,033 & 0,182 & 0,175 & 0,168 \\
\hline $\boldsymbol{w}_{\boldsymbol{i}}$ & \multicolumn{3}{|c|}{0,5} & \multicolumn{3}{|c|}{0,15} \\
\hline & \multicolumn{3}{|c|}{$\boldsymbol{K}_{\mathbf{3 1}}$} & & $\boldsymbol{K}_{\mathbf{3 2}}$ \\
\cline { 2 - 7 } & $v_{L}$ & $v_{C}$ & $v_{L}$ & $v_{C}$ & $v_{L}$ & $v_{C}$ \\
\hline \multirow{2}{*}{$\boldsymbol{A}_{\mathbf{1}}$} & 0,037 & 0,038 & 0,037 & 0,038 & 0,037 & 0,038 \\
\hline $\boldsymbol{A}_{\mathbf{2}}$ & 0,244 & 0,241 & 0,244 & 0,241 & 0,244 & 0,241 \\
\hline $\boldsymbol{A}_{\mathbf{3}}$ & 0,244 & 0,241 & 0,244 & 0,241 & 0,244 & 0,241 \\
\hline $\boldsymbol{A}_{\mathbf{4}}$ & 0,330 & 0,342 & 0,330 & 0,342 & 0,330 & 0,342 \\
\hline $\boldsymbol{A}_{\mathbf{5}}$ & 0,146 & 0,139 & 0,146 & 0,139 & 0,146 & 0,139 \\
\hline
\end{tabular}




\begin{tabular}{|c|c|c|c|c|c|c|}
\cline { 2 - 7 } $\boldsymbol{w}_{\boldsymbol{i}}$ & \multicolumn{3}{|c|}{0,063} & \multicolumn{3}{c|}{0,037} \\
\hline & \multicolumn{3}{|c|}{$\boldsymbol{K}_{\mathbf{4 1}}$} & \multicolumn{3}{c|}{$\boldsymbol{K}_{\mathbf{4 2}}$} \\
\hline & $v_{L}$ & $v_{C}$ & $v_{L}$ & $v_{C}$ & $v_{L}$ & $v_{C}$ \\
\hline $\boldsymbol{A}_{\mathbf{1}}$ & 0,268 & 0,273 & 0,268 & 0,273 & 0,268 & 0,273 \\
\hline $\boldsymbol{A}_{\mathbf{2}}$ & 0,030 & 0,030 & 0,030 & 0,030 & 0,030 & 0,030 \\
\hline $\boldsymbol{A}_{\mathbf{3}}$ & 0,268 & 0,273 & 0,268 & 0,273 & 0,268 & 0,273 \\
\hline $\boldsymbol{A}_{\mathbf{4}}$ & 0,165 & 0,152 & 0,165 & 0,152 & 0,165 & 0,152 \\
\hline $\boldsymbol{A}_{\mathbf{5}}$ & 0,268 & 0,273 & 0,268 & 0,273 & 0,268 & 0,273 \\
\hline $\boldsymbol{w}_{\boldsymbol{i}}$ & \multicolumn{3}{|c|}{0,125} & & & 0,125 \\
\hline
\end{tabular}

Then 81 variants of combinations of local factors were calculated. It is identified that the best alternative options are $A_{3}, A_{4}, A_{1}$. The Table 7 shows mean values of global indices. The indicator $P_{i}$ for all alternative options amounts to 1 which means that at all the DM preference options no change of power generation technology ranking occurs. Judging by the aforementioned, one can draw a conclusion on the sustainability of the obtained results towards DM preference change.

Table 7 Mean indices of global importance factors.

\begin{tabular}{|c|c|c|c|c|c|}
\hline & TPP & WPP & HPP & SPP & DPP \\
\hline$V_{\text {i av }}$ & 0,186 & 0,178 & 0,291 & 0,215 & 0,131 \\
\hline
\end{tabular}

Thus, to conduct the analysis at the second stage the authors adopt the alternative options HPP, SPP, TPP.

At the second stage (Fig.1) the authors corrected the structure of criteria with the account of peculiarities of the selected technology of HPP, SPP, TPP. As the assessment criterion $K_{2}$ the authors selected subcriteria $K_{21}$ - atmospheric pollution, $K_{22}$ - assessment of biological action on flora and fauna, $K_{23}$ - area of withdrawn lands. As the assessment of public opinion in relation to various options of the SGC it is suggested to introduce a subcriterion $K_{33}$ - professional activity risk. In compliance with the method stated in [3] with the application of exact and expert models as well as the system (1) the authors define the following alternative option assessment (Table 8).

Table 8 Assessment of options on criteria.

\begin{tabular}{|c|c|c|c|c|c|c|c|}
\hline \multicolumn{3}{|c|}{$\begin{array}{c}\text { Option, the installed } \\
\text { capacity, MW }\end{array}$} & \multicolumn{2}{|c|}{$\boldsymbol{K}_{\mathbf{1}}$, billion rubles } & $\begin{array}{c}\boldsymbol{K}_{\mathbf{2 1}}, \\
\text { point }\end{array}$ & $\begin{array}{c}\boldsymbol{K}_{22}, \\
\text { poin } \\
\mathbf{t}\end{array}$ \\
\hline & TPP & HPP & SPP & $L$ & $R$ & & \\
\hline$A_{1}$ & 0 & 77 & 70 & $-0,36$ & 4,96 & 0,00 & 6,19 \\
\hline$A_{2}$ & 10 & 67 & 5 & 6,34 & 11,20 & 0,41 & 8,90 \\
\hline$A_{3}$ & 10 & 67 & 10 & 5,35 & 10,21 & 0,41 & 8,51 \\
\hline$A_{4}$ & 10 & 67 & 20 & 3,38 & 8,24 & 0,41 & 7,84 \\
\hline$A_{5}$ & 10 & 67 & 30 & 1,41 & 6,27 & 0,41 & 7,29 \\
\hline$A_{6}$ & 10 & 67 & 40 & $-6,66$ & $-2,27$ & 0,41 & 6,84 \\
\hline$A_{7}$ & 12 & 65 & 0 & 6,10 & 10,87 & 0,50 & 9,22 \\
\hline$A_{8}$ & 20 & 57 & 0 & 1,22 & 5,61 & 0,93 & 8,70 \\
\hline$A_{9}$ & 20 & 57 & 10 & $-0,75$ & 3,64 & 0,93 & 7,93 \\
\hline$A_{10}$ & 30 & 47 & 0 & $-4,16$ & $-0,24$ & 1,21 & 8,05 \\
\hline \multicolumn{7}{|c|}{ Weight of criteria } & \multicolumn{7}{|c|}{0,5} & 0,05 & 0,1 \\
\hline
\end{tabular}

\begin{tabular}{|c|c|c|c|c|c|c|c|c|}
\hline \multicolumn{4}{|c|}{$\begin{array}{l}\text { Option, the installed } \\
\text { capacity, MW }\end{array}$} & \multicolumn{2}{|c|}{$K_{23}, \mathbf{k m}^{2}$} & \multirow{2}{*}{$\begin{array}{c}\begin{array}{c}\boldsymbol{K}_{31}, \\
\text { poin } \\
\mathbf{t}\end{array} \\
4,48\end{array}$} & \multirow{2}{*}{ 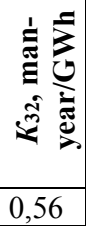 } & \multirow{2}{*}{ 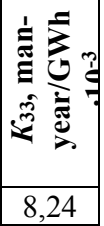 } \\
\hline & TPP & HPP & SPP & $L$ & $R$ & & & \\
\hline$A_{1}$ & 0 & 77 & 70 & 74,70 & 78,20 & 3,94 & 0,29 & 21,60 \\
\hline$A_{2}$ & 10 & 67 & 5 & 75,51 & 76,91 & 4,00 & 0,32 & 21,16 \\
\hline$A_{3}$ & 10 & 67 & 10 & 70,36 & 72,01 & 4,10 & 0,38 & 20,42 \\
\hline$A_{4}$ & 10 & 67 & 20 & 66,66 & 68,81 & 4,19 & 0,42 & 19,82 \\
\hline$A_{5}$ & 10 & 67 & 30 & 62,06 & 64,71 & 4,26 & 0,46 & 19,32 \\
\hline$A_{6}$ & 10 & 67 & 40 & 57,56 & 60,71 & 3,84 & 0,25 & 25,91 \\
\hline$A_{7}$ & 12 & 65 & 0 & 69,75 & 71,13 & 3,74 & 0,23 & 41,18 \\
\hline$A_{8}$ & 20 & 57 & 0 & 49,72 & 52,02 & 3,89 & 0,30 & 38,06 \\
\hline$A_{9}$ & 20 & 57 & 10 & 48,22 & 51,02 & 3,61 & 0,21 & 60,27 \\
\hline$A_{10}$ & 30 & 47 & 0 & 39,58 & 43,03 & 4,48 & 0,56 & 8,24 \\
\hline \multicolumn{4}{|c|}{ Weight of criteria } & \multicolumn{2}{|c|}{0,15} & 0,12 & 0,04 & 0,04 \\
\hline
\end{tabular}

Further, at conducting multi-criteria analysis with the help of a modified method TOPSIS the authors built FSCVF with the help of a DM. By the criteria $K_{1}$, $K_{31}, K_{32}$ importance functions are linear. By other criteria FSCVF has the following form (Fig.6).

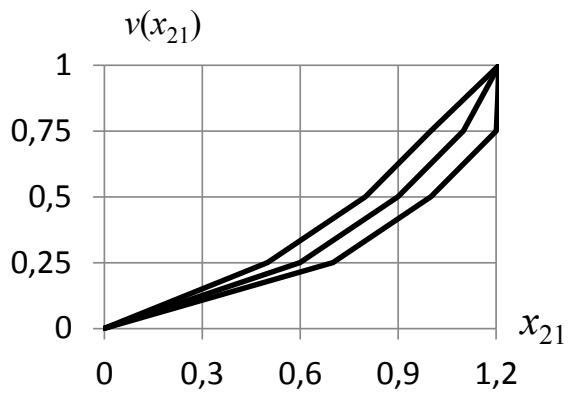

a)

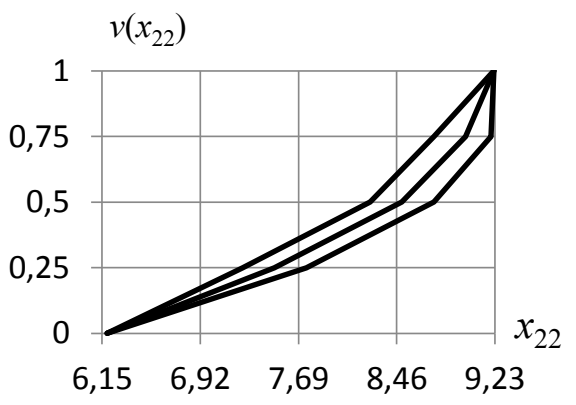

b)

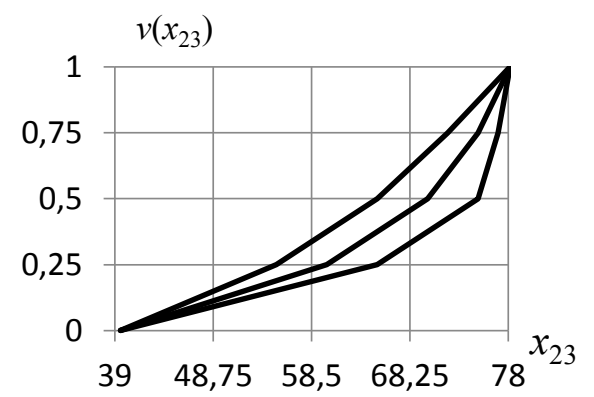

c) 


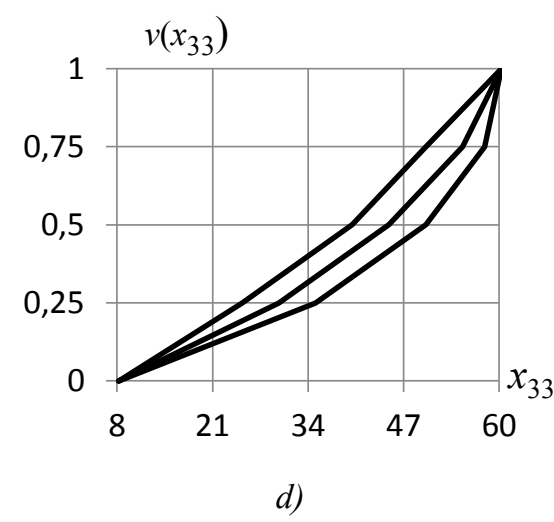

Fig. 6. Fuzzy single-criterion value functions a) atmospheric emissions; b) biological action; c) area of withdrawn lands; $d$ ) professional risk.

As a result of applying the TOPSIS method the authors suggested the following option ranks (Table 9).

Table 9 Final option ranks.

\begin{tabular}{|c|c|c|c|c|c|}
\hline & $A_{1}$ & $A_{2}$ & $A_{3}$ & $A_{4}$ & $A_{5}$ \\
\hline Rank & 0,543 & 0,703 & 0,740 & 0,713 & 0,636 \\
\hline & $A_{6}$ & $A_{7}$ & $A_{8}$ & $A_{9}$ & $A_{10}$ \\
\hline Rank & 0,290 & 0,698 & 0,548 & 0,471 & 0,280 \\
\hline
\end{tabular}

Therefore, the best solution is the option $A_{3}$ : TPP $10 \mathrm{MW}, \mathrm{HPP}-67 \mathrm{MW}$, SPP $-10 \mathrm{MW}$. The obtained solution corresponds to the DM expressed preferences.

\section{Conclusion}

This article suggests a 2-stage method of multi-criteria selection of the preliminary SGC in remote areas. As it can be seen, decision making in relation to the selection of the preliminary SGC stipulates for gathering a large amount of information and complex structure. The proposed method allows to systematize this problem, taking into account the multiplicity of purposes and criteria at the development of energy infrastructure of the newly reclaimed regions, to take into account the uncertainty of initial information and preferences of the DM.

\section{References}

1. Energy strategy of Russia for the period up to 2035 . Developed in accordance with the instructions of the Government of the Russian Federation (Minutes of the meeting of the Government of the Russian Federation of October 30, 2013 No. 38).

2. Saneev B.G., Ivanova I.Yu., Tuguzova T.F. Rol' elektrostantsii maloi moshchnosti $\mathrm{v}$ zonakh detsentralizovannogo energosnabzheniya potrebitelei na vostoke Rossii [The role of small power plants in the areas of decentralized power supply to consumers in the east of Russia]. Ekonomicheskie problemy energeticheskogo kompleksa. 2011, pp. 28-43.

3. Nefedov A.S., Shakirov V. A., Yakovkina T.N. Mnogokriterial'nyi dvukhetapnyi vybor struktury generiruyushchikh moshchnostei $\mathrm{v}$ udalennykh raionakh [Multi-criteria two-stage selection of the structure of generating capacities in remote areas]. Industrial energy. 2019. No. 6. Pp. 7-28.

4. Voropai N.I. Obosnovanie razvitiya elektroenergeticheskikh sistem: Metodologiya, modeli, metody, ikh ispol'zovanie [Justification of the development of electric power systems: Methodology, models, methods, their use]. Novosibirsk, 2015, $448 \mathrm{p}$. 5. Petrovskii A.B. Teoriya prinyatiya reshenii: uchebnik dlya stud. vyssh. ucheb. Zavedenii [Decision theory]. M.: Izdatel'skii tsentr «Akademiya», 2009, $400 \mathrm{p}$.

6. Ramanathan R. A note on the use of the analytic hierarchy process for environmental impact assessment // Journal of Environmental Management, 2001, pp. $27-35$.

7. Abu Taha R., Daim T. Multi-Criteria Applications in Renewable Energy Analysis, a Literature Review. In: Daim, T., et al., Eds., Research and Technology Management in the Electricity Industry, Green Energy and Technology, Springer-Verlag, London, 2013.

8. Rietz R.K., Suryanarayanan S. A review of the application of analytic hierarchy process to the planning and operation of electric power microgrids. 2008 40th North American Power Symposium, pp.1-5. 9. Nefedov A.S., Shakirov V.A. Modifikatsiya protsedury zapolneniya matrits parnykh sravnenii al'ternativ po kriteriyam pri ispol'zovanii metoda analiza ierarkhii [Modification of the procedure for filling matrices of paired comparisons of alternatives by criteria using the hierarchy analysis method]. Information Technology. 2019. T. 25. No. 6. Pp. 331339.

10. Hwang, C.L.; Yoon, K. (1981). Multiple Attribute Decision Making: Methods and Applications. New York: Springer-Verlag.

11.V.A. Shakirov. Mnogokriterial'naya otsenka al'ternativ na osnove teorii poleznosti $\mathrm{v}$ usloviyakh neopredelennosti predpochtenii litsa, prinimayushchego resheniya [Multi-criteria evaluation of alternatives based on the theory of utility in the face of uncertainty in the preferences of the decision maker]. Nechetkie sistemy i myagkie vychisleniya. 2018. Vol. 13. No. 1. pp. 17-35.

12. The official website of the government of Kamchatka Krai. The scheme of territorial planning and location of capital construction objects of regional value dated October 16, 2012 No. 3. URL: http://old.kamgov.ru/index.php?cont $=$ oiv_din\&mcont $=$ $4165 \&$ menu $=4 \& \quad$ menu $2=0 \& i d=172 \quad$ (acessed 11.11.2018)

13. Updated GIS-packages of operational geological information (GIS-Atlas "Nedra of Russia"). URL: http://atlaspacket.vsegei.ru/\#023f61f2999916b05

(acessed 11.11.2018)

14. The official website of the Government of Kamchatka Krai / Business portal of Kamchatka Krai. Investment portal of Kamchatka Krai - TOR "Kamchatka". URL: http://investkamchatka.ru/tor/ (acessed 11.11.2018) 